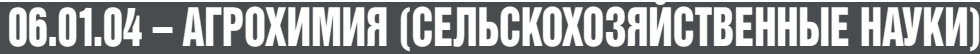

\section{ВЛИЯНИЕ КОМПЛЕКСНОГО ОРГАНОМИНЕРАЛЬНОГО УДОБРЕНИЯ (КОМУ) И БИОПРЕПАРАТОВ НА ПРОДУКТИВНОСТЬ ОЗИМОЙ ПШЕНИЦЫ И БИОЛОГИЧЕСКУЮ АКТИВНОСТЬ ПОЧВЫ В УЛЬЯНОВСКОЙ ОБЛАСТИ}

Захаров Сергей Александрович, научный сотрудник отдела земледелия и технологий возделывания сельскохозяйственных культур

Ульяновский НИИСХ, фолиал СамНЦ РАН

433315, п. Тимирязевский, ул. Институтская 19, 8-842-543-41-32 sergey.zaharov.87@list.ru

\begin{abstract}
Ключевые слова: «КОМУ» комплексное органоминеральное удобрение, Ecoforce, Экстрасол -Ж, БисолБирит, биологическая активность.

В статье приведены результаты испытания комплексного органоминерального удобрения на полях Ульяновского научно-исследовательского института сельского хозяйства. Испытания проводили в течении 3 лет, в трёхкратной повторности на двух фонах. Первый фон - без удобрений. Второй фон - с внесением гранулированного, комплексного органоминерального удобрения (КОМУ) при посеве с нормой внесения 100 кг/га. В последующей схеме на эти два фона накладывались 4 варианта: 1 контроль без биопрепаратов, 2 Eсоforce, 3 Экстрасол-Ж, 4 БисолБифит. Изучено действие биопрепаратов и "КОМУ» на посевах озимой пшеницы, а также выявлена зависимость между биологической активностью почвы и урожайностью на территории Ульяновской области. Наибольший показатель продуктивности пшеницы Харьковская 92 были получены при инокуляции семян препаратами Экстрасол-Ж (1 литр на тонну семян) и БисолБифит на фоне с внесением при посеве комплексного удобрения в дозе 100 кг/га. Внесение комплексного органоминерального удобрения без применения биопрепаратов так же способствовало увеличению биологической активности почвы по сравнению с контролем по фону без удобрений на 5,6\%. В наших исследованиях выявлена прямая зависимость между урожайностью и биологической активности почвы. Уравнение регрессии показывает, что при повышении микробиологической активности на 1\%, урожайность озимой пшеницы возрастает на 0,09 m/2a.
\end{abstract}

\section{Введение}

Развитие сельскохозяйственной отрасли в России напрямую связано с усовершенствованием технологий выращивания сельскохозяйственных культур, которые обеспечивают получение качественной растениеводческой продукции. Разрешение данной цели возможно только лишь при правильном использовании необходимого количества ресурсов, в числе которых большая роль принадлежит снабжению культурных растений азотом и элементами питания [1].

Внесение необоснованных доз минеральных удобрений, а также технология внесения оказывают негативное влияние на окружающую среду. Происходит снижение плодородия, качества растениеводческой продукции, ухудшение свойств почвы и загрязнение атмосферы и при- родных вод $[2,3,4,5]$.

Большая часть полезных веществ удобрений вымывается в грунтовые воды, улетучивается в атмосферу либо становится недоступной для растений формой. При этом внесение удобрений не всегда является оправданным способом и дает дополнительную прибавку в урожае, так как цена на них ежегодно возрастает. Соответственно нужно максимально использовать все качественные факторы для увеличения отдачи от каждого килограмма минерального удобрения, вносимого под ту или иную культуру [6, $7,8,9]$. В сельскохозяйственном производстве в последние годы имеет огромное значение применение современных биопрепаратов, в состав которых входят ризосферные бактерии, обеспечивающие растения элементами питания и тем самым снижающие количество применяемых 
агрохимикатов [10, 11, 12].

Анализ литературных данных показывает, что положительное воздействие микроорганизмов вызвано не только улучшением питания растений азотом, но и влиянием физиологически активных веществ, которые не оказывают негативного действия на окружающую среду и экономически выгодны [13, 14, 15].

\section{Материалы и методы исследований}

Задача исследований: определить воздействие комплексного гранулированного органоминерального удобрения (КОМУ) в сочетании с биологическими препаратами на продуктивность озимой пшеницы (сорт Харьковская 92) и биологическую активность почвы.

Почва участка, выбранного для закладки опыта, - чернозём выщелоченный среднемощный среднесуглинистый, содержание гумуса - 5,58 \%, азота - 0,27\%, валового фосфора - 0,078 \%, К О 214 и 102 мг/кг почвы, рН опытного участка 6,5.

Закладки опытов проводили на полях Ульяновского НИИСХ в течение 3 лет в трёхкратной повторности на двух фонах. Первый фон - без удобрений. Второй фон - с внесением гранулированного, комплексного органоминерального удобрения (КОМУ) при посеве с нормой внесения 100 кг/га. В последующей схеме на эти два фона накладывались 4 варианта: 1. контроль без биопрепаратов, 2. Ecoforce, 3. Экстрасол-Ж, 4. БисолБифит.

Обработку посевного материала озимой пшеницы проводили согласно схеме опыта.

Контрольный вариант - без обработки семян

Ecoforce - 1л на тонну семян. Позволяет оптимизировать развитие растений, получать существенные прибавки урожая высокого качества, а также помогает усваивать азотные удобрения.

БисолБифит - предназначен для предпосевной обработки семян и нанесения препарата на гранулы минеральных удобрений в специальных смесительных устройствах (штамм ризосферных бактерий Basillus subtilus Ч-13).

Экстрасол-Ж - штамм ризосферных бактерий Basillus subtilus, с содержанием не менее 100 млн. KOE в 1 г препарата.

Для фонового внесения было выбрано гранулированное комплексное органоминеральное удобрение (КОМУ), размер гранул- 2-4 мм. Содержание макроэлементов: N (1,95\%), P (28,8\%), K (7,5\%). Удобрение содержит микроэлементы, такие как $\mathrm{Cu}, \mathrm{Zn}, \mathrm{Co}, \mathrm{Fe}, \mathrm{Mn}$. Преимущество КОМУ: в дозе 100 кг/га по азоту заменяет 0,5 т навоза; 13,5 т навоза по фосфору; 0,5 т навоза по калию; 130 кг простого суперфосфата, содержит органическое вещество.

Данные испытания проводили согласно общепринятому ГОСТу. Математическая обработка была проведена методом дисперсионного анализа программой Agros.

\section{Результаты исследований}

Изучение биологической активности почвы проводили методом льняных полотен. Было установлено, что наименьшее разложение льняного полотна отмечено на контрольном варианте на фоне без удобрений, где этот показатель составил 34,3\%. Внесение комплексного органоминерального удобрения позволило повысить данный показатель до 39,9\%, что на 5,6\% выше контрольного варианта. Обработка семян препаратами Ecoforce, Бисолбифит и Экстрасол-Ж

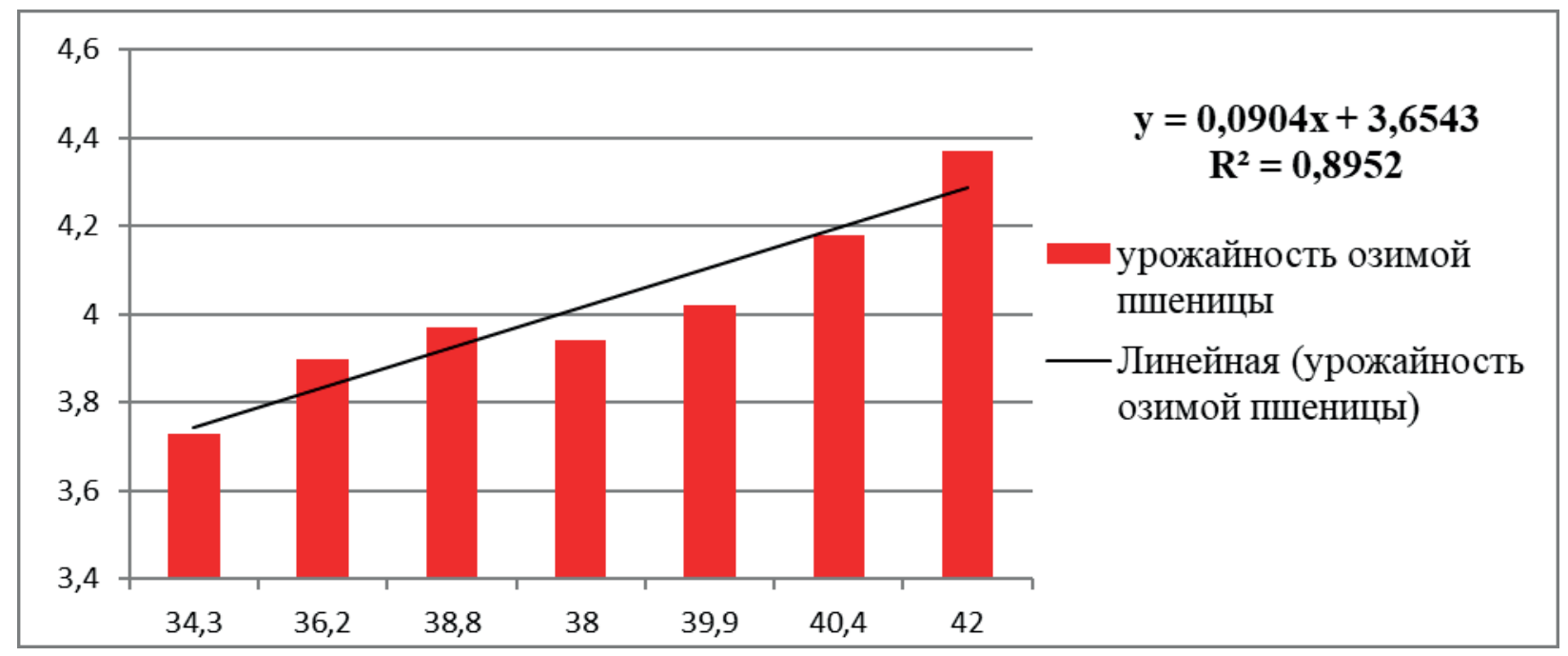

Рис.1 - Урожайность озимой пшеницы (сорт Харьковская-92) в зависимости от биологической активности почвы. 
Таблица 1

Урожайность озимой пшеницы и биологическая активность почвы, (в среднем за 3 года)

\begin{tabular}{|c|c|c|c|c|}
\hline Фон & Вариант & Урожайность т/га & $\begin{array}{c}\text { Прибавка к контролю, } \\
\%\end{array}$ & $\begin{array}{c}\text { Биологическая актив- } \\
\text { ность почвы 0-30 см, } \\
\% \\
\end{array}$ \\
\hline \multirow{4}{*}{ 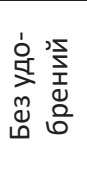 } & Контроль & 3,73 & - & 34,3 \\
\hline & Ecoforce & 3,90 & 4,5 & 36,2 \\
\hline & Экстрасол-Ж & 3,97 & 6,4 & 38,8 \\
\hline & БисолБифит & 3,94 & 5,6 & 38,0 \\
\hline \multirow{4}{*}{ 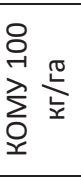 } & Контроль & 4,02 & 7,7 & 39,9 \\
\hline & Ecoforce & 4,18 & 12,0 & 40,4 \\
\hline & Экстрасол-Ж & 4,37 & 17,1 & 42,0 \\
\hline & БисолБифит & 4,40 & 17,9 & 41,3 \\
\hline \multicolumn{5}{|c|}{$\begin{array}{l}\mathrm{HCP}_{05} \text { Фактор A - 0,15 Фактор B - 0,17 Фактор AB -0,32 } \\
\mathrm{HCP}_{05} \text { Фактор A - 0,10 Фактор B - 0,13 Фактор AB -0,23 } \\
\mathrm{HCP}_{05} \text { Фактор A - 0,16 Фактор B - 0,18 Фактор AB -0,34 }\end{array}$} \\
\hline
\end{tabular}

также способствовала повышению целюлозоразлагающей активности почвы. Входящие в состав препаратов Экстрасол-Ж, и БисолБифит штаммы азотфиксирующих бактерий оказали положительное действие на биологические процессы, протекающие в почве как на фоне без удобрения, так и на фоне применения КОМУ. В наших исследованиях были получены максимальные значения разложения льняной ткани по вариантам с применением биоудобрений на фоне «КОМУ» - 41,3 - 42,0\% соответственно.

Внесение комплексного органоминерального удобрения без применения биопрепаратов также способствовало увеличению биологической активности почвы по сравнению с контролем по фону без удобрений на 5,6\%

Проведенный нами корреляционный анализ показывает прямую зависимость между урожайностью и биологической активностью почвы. Уравнение регрессии показывает, что при повышении микробиологической активности на 1 \% урожайность озимой пшеницы возрастает на 0,09 т/га (рис.1).

Благоприятными условиями для налива зерна могут являться как ростостимулирующее действие биопрепарата, так и амелиорация минерального питания растений за счёт усиления адсорбции элементов питания из почвы и фиксирования азота микроорганизмами $[16,17]$.

Биологические особенности озимых культур отличаются от яровых. Вегетационный период в отличие от яровых начинается осенью и заканчивается летом следующего года. Тем самым озимая пшеница использует два более благоприятных периода, осень и весну, поэтому урожайность обладает большим потенциалом, чем у яровой пшеницы.
Большое значение для получения высоких урожаев играет внесение удобрений. В наших исследованиях применяемое удобрение «КОМУ» в дозе 100 кг/га способствовало достоверной прибавке урожая на 7,7 \%. Предпосевная обработка семян препаратами Ecoforce, Экстрасол-Ж и БисолБифит также повышает урожайность культуры, на вариантах изучения прибавка составила от 0,17 до 0,21 т/га. Увеличение урожайности от применения биопрепаратов в среднем составило 5-6 \%.

Совместное использование биологических препаратов на фоне органоминерального удобрения оказало максимальное действие на продуктивность озимой пшеницы. Азотфиксирующие бактерии, входящие в состав препаратов Экстрасол-Ж и БисолБифит, способствовали ускоренной мобилизации элементов питания, что положительно сказалось на урожайности. Максимальные значения в наших исследованиях были получены с применением данных препаратов, где сформировалась урожайность 4,37 - 4,40 т/га и превзошла контрольный вариант на 0,64 - 0,67 т/га или 17,1 - 17,9 \%. Использование Ecoforce на фоне "КОМУ» также увеличило урожайность на $12 \%$, при этом валовой сбор составил 4,18 т/га.

\section{Обсуждение}

Проведенные нами исследования показали, что применение комплексного органоминерального удобрения и биопрепаратов оказывает положительное влияние на биологическую активность почвы и увеличивает этот показатель до 42\% и относительно контрольного варианта превышает на 8\%. Таким образом была выявлена тесная взаимосвязь между биологическими процессами протекающими в почве и продук- 
тивностью озимой пшеницы. Об этом свидетельствует полученная в опыте урожайность, которая за годы исследования превысила контрольный вариант на 0,67 т/га.

\section{Заключение}

В результате проведенного опыта на полях Ульяновского НИИСХ можно сделать следующие выводы. Выявлена тесная связь между урожайностью и биологической активностью почвы. При увеличении микробиологической активности почвы, изучаемой методом льняных полотен, происходило увеличение сбора зерна с гектара. Использование биопрепаратов Экстрасол-Ж и БисолБифит для обработки семян озимой пшеницы в сочетании с внесением комплексного органоминерального удобрения «КОМУ» под предпосевную культивацию способствовало формированию более высокой урожайности в период исследований, что позволило получить достоверную прибавку на уровне 0,62 - 0,67 т/га по отношению к контрольному варианту.

\section{Библиографический список}

1. Завалин, А. А. Биопрепараты, удобрения и урожай / А. А. Завалин. - Москва : ВНИИА, 2005. -302 с.

2. Обоснование использования удобрительномелиорирующей смеси на основе торфа и сапропеля для повышения плодородия деградированных почв / Л. В. Кирейчева, А. В. Нефедов, К. Н. Евсенкин, А. В. Ильинский, Д. В. Виноградов, Н. А. Иванникова // Вестник РГАТУ. - 2016. - № 3. - С.12-18.

3. Щур, А. В. Влияние различных уровней агроэкологических нагрузок на биохимические характеристики почвы / А. В. Щур, Д. В. Виноградов, В.П.Валько // Юг России: экология, развитие. - 2016. - Т.11, № 4. C.139-148.

4. Отраслевая экология / А. В. Щур, Д. В. Виноградов, Н. Н. Казаченок, В. П. Валько, О. В. Валько. - Рязань : ИПД Первопечатникъ, 2016. - 154 с. Потапова, Л. В. Экологические аспекты использования комплексного органоминерального удобрения культифорт марка: культифорт культимарт на картофеле/ Л. В. Потапова, О. В. Лукьянова // Здоровая окружающая среда - основа безопасности регионов : материалы первого Международного экологического форума в Рязани. - Рязань, 2017. - С. 256-260.

5. Чеботарь, В. К. Применение биомодифицированных минеральных удобрений : монография / В. К. Чеботарь, А. А. Завалин, А. Г. Ариткин. -Москва:ВНИИА ; Ульяновск : УлГУ, 2014. -142 с.

6. Лапа, В. В. Влияние различных систем применения минеральных удобрений на урожайность и качество ячменя на дерново-подзолистой супесчаной почве / В. В. Лапа, Н. Н. Ивахненко // Агрохимия. - 2000. - № 11. - C. 34-40.

7. Сайдяшева, Г. В. Эффективность последействия органических и нетрадиционных удобрений при возделывании яровой пшеницы в Среднем Поволжье: спец. 06.01.04 : автореферат диссертации на соискание ученой степени кандидата сельскохозяйственных наук / Сайдяшева Галина Владимировна ; Мордовский государственный университет им. Н.П. Огарева. - Ульяновск, 2011. - 19 c.

8. Сайдяшева, Г.В.Эффективность применения минеральных, биоминеральных удобрений и биопрепарата бисолбифит на посевах яровой пшеницы в условиях среднего Поволжья / Г. В. Сайдяшева, С. А. Захаров // Вестник Ульяновской государственной сельскохозяйственной академии. - 2017. - № 1(37). - С. 56-65.

9. Оценка эффективности микробных препаратов в земледелии / под редакцией А. А Завалина. - Москва : Россельхозакадемия, 2000. - 82 с.

10. Boddey, R. M. Nitrogen fixation with grasses and cereals: recent results and perspectives for future research / R. M. Boddey, J. Dobereiner // Plant and Soil. - 1988. Vol.108(1). - P. 53-65.

11. Курсаков, В. С. Развитие растений яровой пшеницы при использовании биопрепаратов на фоне минеральных удобрений / В. С. Курсаков, Т. Г. Хижникова, В. А. Зиновьева // Вестник Алтайского государственного аграрного университета. - 2019. - № 3 (173). - С.1218.

12. Дериглазова, Г. М. Влияние природных и антропогенных факторов на урожай и качество ярового ячменя / Г. М. Дериглазова // Земледелие. - 2012. - № 6. - C. 43-45.

13. Tikhonovich, I. A. Prospects for utilization of the root bacillus diazotrophs in agriculture / I. A. Tikhonovich // Biological Nitrogen Fixation for the 21stCentury. Proc. 11th Int. Cong. On Nitr. Fix.,Institut Pasteur. Paris. July 20-25. 1997. - P. 613.

14. Сайдяшева, Г.В.Эффективность применения биоминеральных, минеральных удобрений и биопрепарата бисолбифит при возделывании ярового ячменя в Среднем Поволжье / Г. В. Сайдяшева, Е. В. Кузина // Пермский аграрный вестник. - 2018. - №4(24). - С. 82-89.

15. Geographical regularities of effect of inoculation with associative diazotrophs on the productivity of cereals / A. A. Zavalin [et al.] // Plant Microbial Interactions: Positive interactions in relation to crop production and utilisation Aspects of Applied Biology 63. - 2001. - P. 123-127.

16. Лебедев, В. Н. Перспективность инокуляции семян горчицы белой и сарептской ассоциативными азотфиксирующими штаммами ризобактерий / В. Н. Лебедев, Г. А. Ураев // Пермский аграрный вестник. 2015. - № 3 (11). - C.21-25. 


\title{
INFLUENCE OF COMPLEX ORGANOMINERAL FERTILIZER (COMF) AND BIOPRODUCTS ON PRODUCTIVITY OF WINTER WHEAT AND BIOLOGICAL SOIL ACTIVITY IN ULYANOVSK REGION
}

\author{
Zakharov S.A. \\ Ulyanovsk Research Institute of Agriculture, branch of SamSC RAS. \\ Email: sergey.zaharov.87@list.ru
}

Key words: "COMF" complex organomineral fertilizer, Ecoforce, Extrasol-Zh, BisolBifit, biological activity.

The article presents results of testing a complex organomineral fertilizer on the fields of Ulyanovsk Research Institute of Agriculture. The tests were carried out for 3 years, in three replications, on two backgrounds. The first background is without fertilizers. The second background is with introduction of granular, complex organomineral fertilizer (COMF) during sowing with an application rate of $100 \mathrm{~kg} / \mathrm{ha}$. In the subsequent scheme, four options were used on these two backgrounds: 1 control without bio products, 2 Ecoforce, 3 Extrasol-Zh, 4 BisolBifit. The effect of biological products and "COMF "on winter wheat crops has been studied, and the relationship between soil biological activity and productivity in Ulyanovsk region has been revealed. The highest productivity parameter of Kharkovskaya 92 wheat was obtained by inoculation of seeds with Extrasol-Zh (1 liter per ton of seeds) and BisolBifit on complex fertilizer background during sowing at a dose of $100 \mathrm{~kg} / \mathrm{ha}$. Introduction of a complex organomineral fertilizer without application of biological products also contributed to an increase of soil biological activity in comparison with the control background without fertilizers by $5.6 \%$. Our research has revealed a direct relationship between yield and soil biological activity. The regression equation shows that winter wheat yield increases by $0.09 t /$ ha with an increase of microbiological activity by $1 \%$.

Bibliography:

1. Zavalin, A. A. Biological products, fertilizers and harvest / A. A. Zavalin. - Moscow: All-Russian Research Institute of Automation, 2005.- 302 p.

2. Justification for usage of a fertilizer-reclamation mixture based on peat and sapropel for fertility increase of degraded soils / L. V. Kireicheva, A. V. Nefedov, K. N. Evsenkin, A. V. Ilyinskiy, D. V. Vinogradov, N. A. Ivannikova //Vestnik of RSATU. - 2016. - № 3. - P.12-18.

3. Shchur, A.V. The influence of different levels of agroecological loads on soil biochemical characteristics/A. V. Shchur, D. V. Vinogradov, V. P. Valko//South of Russia: ecology, development. - 2016. - V.11, № 4. - P.139-148.

4. Branch ecology / A. V. Shchur, D. V. Vinogradov, N. N. Kazachenok, V. P. Valko, O. V. Valko. - Ryazan: Publishing house Pervopechatnik, $2016 .-154$ p.

5. Potapova, L.V. Ecological aspects of usage of complex organomineral fertilizer Cultifort mark: Cultifort cultimart on potatoes / L. V. Potapova, O. V. Lukiyanova // Healthy environment is the basis for regional security: materials of the first International Ecological Forum in Ryazan. - Ryazan, 2017. -P. 256-260.

5. Chebotar, V.K. Application of biomodified mineral fertilizers: monograph / V.K. Chebotar, A.A. Zavalin, A.G. Aritkin. - Moscow: All-Russian Research Institute of Automation; Ulyanovsk: UISU, 2014.- 142 p.

6. Lapa, V.V. Influence of various systems of application of mineral fertilizers on barley yield and quality on sod-podzolic sandy loamy soil / V.V. Lapa, N.N. Ivakhnenko // Agrochemistry. - 2000. - № 11. - P. 34-40.

7. Saidyasheva, G.V. Effectiveness of the aftereffect of organic and non-traditional fertilizers in cultivation of spring wheat in the Middle Volga region: spec. 06.01.04: author's abstract of dissertation for the degree of candidate of agricultural sciences / Saidyasheva Galina Vladimirovna; Mordovian State University named after N.P. Ogarev. - Ulyanovsk, 2011.- 19 p.

8. Saidyasheva, G.V. The effectiveness of usage of mineral, biomineral fertilizers and bisolbifit bioproduct on spring wheat crops in the middle Volga region / G.V. Saidyasheva, S.A. Zakharov // Vestnik of Ulyanovsk State Agricultural Academy. - 2017. - № 1 (37). - P. 56-65.

9. Evaluation of the effectiveness of microbial products in agriculture / edited by A. A. Zavalin. - Moscow: Russian Agricultural Academy, $2000 .-82$.

10. Boddey, R. M. Nitrogen fixation with grasses and cereals: recent results and perspectives for future research / R. M. Boddey, J. Dobereiner // Plant and Soil. - 1988. - Vol.108 (1). - P. 53-65.

11. Kursakov, V. S. Development of spring wheat plants in case of application of biological products in combination with mineral fertilizers / V. S. Kursakov, T. G. Khizhnikova, V. A. Zinovieva // Vestnik of Altai State Agrarian University. - 2019. - № 3 (173). - P. 12-18.

12. Deriglazova, G.M. Influence of natural and anthropogenic factors on yield and quality of spring barley / G.M. Deriglazova // Agriculture. - 2012. - No 6. - P. 43-45

13. Tikhonovich, I. A. Prospects for utilization of the root bacillus diazotrophs in agriculture /I. A. Tikhonovich // Biological Nitrogen Fixation for the 21st Century. Proc. 11th Int. Cong. On Nitr. Fix., Institut Pasteur. Paris. July 20-25. - 1997. - P. 613.

14. Saidyasheva, G.V. The effectiveness of application of biomineral, mineral fertilizers and bisolbifit bioproduct in cultivation of spring barley in the Middle Volga region / G.V. Saidyasheva, E.V. Kuzina // Perm Agrarian Vestnik. - 2018. - № 4 (24). - P. 82-89.

15. Geographical regularities of effect of inoculation with associative diazotrophs on the productivity of cereals / A. A. Zavalin [et al.] // Plant Microbial Interactions: Positive interactions in relation to crop production and utilization Aspects of Applied Biology 63. - 2001. - P. 123-127.

16. Lebedev, V.N. The prospect of inoculation of white and Sarepta mustard seeds with associative nitrogen-fixing strains of rhizobacteria / V.N. Lebedev, G.A. Uraev // Perm Agrarian Vestnik. - 2015. - № 3 (11). - P.21-25. 